\title{
Route of administration for illicit prescription opioids: a comparison of rural and urban drug users
}

April M Young ${ }^{1,2+}$, Jennifer R Havens ${ }^{1 *+}$, Carl G Leukefeld ${ }^{1 \dagger}$

\begin{abstract}
Background: Nonmedical prescription opioid use has emerged as a major public health concern in recent years, particularly in rural Appalachia. Little is known about the routes of administration (ROA) involved in nonmedical prescription opioid use among rural and urban drug users. The purpose of this study was to describe rural-urban differences in ROA for nonmedical prescription opioid use.

Methods: A purposive sample of 212 prescription drug users was recruited from a rural Appalachian county $(n=101)$ and a major metropolitan area $(n=111)$ in Kentucky. Consenting participants were given an intervieweradministered questionnaire examining sociodemographics, psychiatric disorders, and self-reported nonmedical use and ROA (swallowing, snorting, injecting) for the following prescription drugs: buprenorphine, fentanyl, hydrocodone, hydromorphone, methadone, morphine, OxyContin ${ }^{\circledast}$ and other oxycodone.
\end{abstract}

Results: Among urban participants, swallowing was the most common ROA, contrasting sharply with substancespecific variation in ROA among rural participants. Among rural participants, snorting was the most frequent ROA for hydrocodone, methadone, OxyContin ${ }^{\oplus}$, and oxycodone, while injection was most common for hydromorphone and morphine. In age-, gender-, and race-adjusted analyses, rural participants had significantly higher odds of snorting hydrocodone, OxyContin ${ }^{\circledR}$, and oxycodone than urban participants. Urban participants had significantly higher odds of swallowing hydrocodone and oxycodone than did rural participants. Notably, among rural participants, $67 \%$ of hydromorphone users and $63 \%$ of morphine users had injected the drugs.

Conclusions: Alternative ROA are common among rural drug users. This finding has implications for rural substance abuse treatment and harm reduction, in which interventions should incorporate methods to prevent and reduce route-specific health complications of drug use.

\section{Background}

There has been a meteoric rise in the rates of illicit prescription opioid use and dependence in the US in recent years $[1,2]$. According to the National Survey on Drug Use and Health, prescription opioid nonmedical use has quadrupled in the last 20 years [3] and, among new initiates to illicit drug use, has surpassed marijuana use [4]. Further, it appears that nonmedical prescription opioid use is particularly problematic in rural areas encompassing Appalachian Kentucky, Virginia and West

\footnotetext{
* Correspondence: jennifer.havens@uky.edu

+ Contributed equally

${ }^{1}$ Center on Drug and Alcohol Research, Department of Behavioral Science,

University of Kentucky College of Medicine, Lexington, KY, USA

Full list of author information is available at the end of the article
}

Virginia [5,6]. The health consequences of nonmedical prescription opioid use can be severe; long-term use can lead to physical dependence and addiction, and, at highdoses, the drugs can cause severe respiratory distress and death [7]. The motives for nonmedical use of prescription drugs are various, but studies have identified one of the most common to be individuals' desire to relieve physical pain [8]. Some evidence suggests that chronic nonmalignant pain may be greater in rural areas of the US [9], but without further research, proposed links between the rural burden of nonmalignant pain and nonmedical prescription opioid use are largely speculative. The growing burden of nonmedical prescription drug use in America and its unique manifestations in rural areas has warranted more research. For example, 
differences between characteristics of rural and urban prescription opioid use have been examined using data from signal detection systems [10], methadone maintenance treatment enrollees [11], probationers [12], and drug-related medical examiner cases [13]. However, to our knowledge, there are no reports on rural-urban differences in ways in which individuals are administering prescription opioids.

Route of drug administration has important implications on users' health outcomes, including risk of dependence, susceptibility to infection, and experience of route-specific health complications [14]. Injection drug users, in particular, are at a heightened risk for HIV and hepatitis C infection [15-18], drug dependence [19-21], and overdose [22]. Individual-level risk factors related to transitioning to injection drug use (IDU) from other routes of administration include unemployment [23], insecure income source [24], homelessness [23,25-27], school dropout [24], and early-onset substance abuse [28]. The extent of individuals' previous substance use $[23,25]$ and frequency of substance use $[26,27]$ have also been identified as correlates. A number of social and ecological factors also play a role in drug users' risk for transitioning to injection. Perceived social support or tolerance for injection [23,26], social pressure [29], and geographic proximity to dealers [30] and other IDUs [31], as well as having a friend [25], sex partner [23,32], or family member who engages in IDU [24], are also associated with transitioning to injection. Drug markets [33], drug availability [30,34], and social norms surrounding typical routes of administration, collectively referred to as "site ecology" can also play a role [27]. Temporal trends in transitions to injection sometimes precipitated by changes in drug availability have also been identified $[35,36]$. Non-injection routes of administration are typically more expensive in terms of 'bang per buck', thus transitioning to IDU can also entail economic motivation [35]. Previous studies have shown that drug price [30] and cost-effectiveness $[27,29]$ can play a role in determining patterns in routes of administration as well.

Studies suggest that nonmedical prescription opioid use can involve various routes of administration, the choice of which can be influenced by demographic factors such as gender and age [37-41]. However, the influence of rurality on routes of administration for nonmedical prescription opioid use has not been explored. The purpose of this study was to describe rural-urban differences in routes of administration for: buprenorphine, fentanyl, hydrocodone, hydromorphone, methadone, morphine, OxyContin ${ }^{\circ}$, and oxycodone.

\section{Methods}

A total of 212 participants entered the study in two Kentucky counties, one a non-metropolitan Appalachian county and the other in a metropolitan area of the state's Bluegrass region [42]. The rural county has been designated by the Appalachian Regional Commission as economically depressed [43]. Both counties are predominantly white (97.3\% and $77.4 \%$, respectively) [44].

Participants were recruited using snowball sampling, which is most commonly used to access hidden populations such as drug users [45]. In the current study, participants who were initially recruited with flyers or by community key informants who agreed to participate in the study were asked to refer additional participants, who in turn were asked to refer additional participants and so on. Participants were eligible if they reported having used any prescription opioid nonmedically in the prior 30 days and OxyContin $^{\circ}$ at least once in the prior three years (either medically or non-medically). The purposive sampling of OxyContin users is a product of the purpose of the overall goal of the study, which was to compare outcomes of OxyContin use among rural and urban drug users.

Data were collected between October 2008 and August 2009. Interviewers were three research assistants who resided in the target communities. After determining eligibility and obtaining informed consent, an interviewer-administered questionnaire was utilized to gather information on socio-demographic, medical, family/ social characteristics, and self-reported behaviors. The MINI International Neuropsychiatric Interview, version 5.0 [46] was used to measure the following psychiatric disorders: major depressive disorder (MDD), generalized anxiety disorder (GAD), post-traumatic stress disorder (PTSD) and antisocial personality disorder (ASPD). Drug problem severity was examined using a composite score from the Addiction Severity Index (ASI) [47]. For the purposes of the current study, participants were also asked to indicate lifetime and recent (past 30 day) use of the following substances for the purposes of getting high: buprenorphine (e.g., Subutex ${ }^{\circ}$, Suboxone ${ }^{\circ}$ ), fentanyl patch, hydrocodone (e.g., $\mathrm{Norco}^{\circ}$, Vicodin ${ }^{\circ}$, Lorcet ${ }^{\circ}$, Lortab $\left.^{\circ}\right)$, hydromorphone (Dilaudid $\left.{ }^{\circ}\right)$, methadone tablets, morphine (e.g., MSContin ${ }^{\circ}, \mathrm{Kadian}^{\circ}$, Avinza ${ }^{\circ}$ ), OxyCon$\operatorname{tin}^{\circ}$ (tablets and generic), and other oxycodone (e.g., Tylox $^{\circ}$, Percocet ${ }^{\ominus}$, Percodan $^{\circ}$ ). For each specific drug for which participants reported lifetime use, they were asked about the frequency of using the following routes of administration: swallowing (including swallowing whole and chewing to swallow), snorting, and injecting. Participants were interviewed in locations such as a library or other public places and were compensated $\$ 50$ for their time. The study was approved by the University of Kentucky Institutional Review Board.

\section{Analysis}

The dependent variable of interest was substance-specific route of administration (i.e. for each substance, there 
were three dichotomous outcomes defined by lifetime engagement in swallowing, injecting, and/or snorting as a route of administration). Categorical and continuous demographic characteristics of rural and urban drug users were compared using chi-square tests and MannWhitney U-tests, respectively. Logistic regression analysis was used to examine differences between rural and urban participants' route of administration, adjusting for age, gender, and race. The statistical software SPSS Version 17.0 (SPSS Inc., Chicago, IL) was used to conduct data analysis.

\section{Results}

\section{Description of the sample}

Descriptive characteristics of the sample $(\mathrm{n}=212)$ are displayed in Table 1. Rural drug users comprised $47.6 \%$ $(\mathrm{n}=101)$ of the sample. The median age of all participants was 37 years and ranged from 20 to 69 . The majority of participants were men (54\%) and $51 \%$ were non-Hispanic white. The median number of years of formal education completed was 12 . Just under half (49\%) had been employed in the past 30 days and 20\% were receiving pension for disability. The median monthly legal income was $\$ 665$ and most participants (59\%) did not have health insurance. Just over $21 \%$ were married or remarried, $34 \%$ were widowed, separated, or divorced, and $45 \%$ had never been married. Rural participants were significantly younger, had fewer years of formal education, earned less income than urban participants, and had significantly higher drug problem severity scores on the Addiction Severity Index. Significantly more rural participants were non-Hispanic white, nonreligious, and married or remarried than were urban participants.

Approximately half (46\%) of participants had ever enrolled in drug or alcohol treatment. Fifty percent of the sample reported that they had a chronic medical problem and $44 \%$ were regularly taking prescribed medication for a physical problem. Significantly more urban participants were regularly taking prescribed medication for a physical problem than rural participants. Approximately $35 \%$ of participants met the DSM-IV criteria for major depressive disorder (MDD), 37\% for generalized anxiety disorder (GAD), 16\% for post-traumatic stress disorder (PTSD), and 30\% for anti-social personality disorder (ASPD). Significantly more rural participants met criteria for MDD than did urban participants (Table 1).

\section{Drug Use and Route of Administration}

Table 2 describes rural and urban nonmedical drug use and the routes of drug administration for each of the drugs. No urban participants reported lifetime use of buprenorphine or of the fentanyl patch. Among rural participants, however, 51\% reported buprenorphine use and $37 \%$ reported fentanyl use, both of which were most commonly administered by swallowing. Interestingly,

Table 1 Comparison of demographic characteristics for rural $(n=101)$ and urban $(n=111)$ drug users

\begin{tabular}{|c|c|c|c|c|}
\hline Descriptive characteristics & $\begin{array}{l}\text { Rural } \\
n(\%)\end{array}$ & $\begin{array}{l}\text { Urban } \\
n(\%)\end{array}$ & $\begin{array}{l}\text { Total } \\
n(\%)\end{array}$ & $P$ value \\
\hline Male & $57(58.2)$ & $56(50.9)$ & $113(54.3)$ & 0.294 \\
\hline White & $96(95.0)$ & $11(9.9)$ & $107(50.5)$ & $<0.001$ \\
\hline Age - median (IQR) & $33(27-43)$ & $42(30-49)$ & $37(29-47)$ & 0.004 \\
\hline Years in county - median (IQR) & $31.0(25-37)$ & $30.5(16.5-43)$ & $31.0(23-41)$ & 0.467 \\
\hline Years of formal education - median (IQR) & $12.0(9-12)$ & $12(12-14)$ & $12.0(10-12.5)$ & $<0.001$ \\
\hline Recent legal income*- median (IQR) & $\$ 600(300-800)$ & $\$ 720.50(468-1289)$ & $\$ 665(400-1020)$ & 0.003 \\
\hline Employed in Past 30 Days & $43(42.6)$ & $61(55.0)$ & $104(49.1)$ & 0.072 \\
\hline Receives Pension for Disability & $21(20.8)$ & $21(18.9)$ & $42(19.8)$ & 0.733 \\
\hline Married/Remarried & $29(28.7)$ & $16(14.4)$ & $45(21.2)$ & 0.011 \\
\hline Non-religious & $64(63.4)$ & $30(27.0)$ & $94(44.3)$ & $<0.001$ \\
\hline Uninsured & $57(56.4)$ & $68(61.3)$ & $125(59.0)$ & 0.488 \\
\hline Has Chronic Medical Problem & $57(56.4)$ & $49(44.1)$ & $106(50.0)$ & 0.074 \\
\hline Prescribed Medication for Physical Problem & $36(35.6)$ & $58(52.3)$ & $94(44.3)$ & 0.015 \\
\hline Ever Treated for Drug/Alcohol Problem & $49(48.5)$ & $48(43.2)$ & $97(45.8)$ & 0.442 \\
\hline ASI Composite Drug Use Score - median (IQR) & $0.26(0.14-0.34)$ & $0.08(0.03-0.17)$ & $0.16(0.06-0.28)$ & $<0.001$ \\
\hline \multicolumn{5}{|l|}{ Psychiatric characteristics } \\
\hline Major Depressive Disorder & $47(46.5)$ & $28(25.2)$ & $75(35.4)$ & 0.001 \\
\hline Generalized Anxiety Disorder & $41(40.6)$ & $38(34.2)$ & $79(37.3)$ & 0.339 \\
\hline Post-traumatic Stress Disorder & $20(19.8)$ & $13(11.7)$ & $33(15.6)$ & 0.105 \\
\hline Anti-social Personality Disorder & $32(31.7)$ & 31 (27.9) & $63(29.7)$ & 0.550 \\
\hline
\end{tabular}

IQR - Interquartile range, ASI - Addiction Severity Index [47].

*Income in past 30 days from employment, unemployment compensation, welfare, pension, benefits, social security, mate, family, friends, or child support. 
Table 2 Age-, gender-, and race-adjusted comparisons for route of drug administration among rural $(n=101)$ and urban $(n=111)$ drug users

\begin{tabular}{|c|c|c|c|}
\hline & $\begin{array}{l}\text { Rural } \\
\%\end{array}$ & $\begin{array}{l}\text { Urban } \\
\%\end{array}$ & $\begin{array}{l}\text { Adjusted* } \\
P \text {-values }\end{array}$ \\
\hline Buprenorphine (sublingual tablets) & 50.5 & 0 & - \\
\hline Swallowing & 31.7 & 0 & - \\
\hline Snorting & 26.7 & 0 & - \\
\hline Injecting & 3.0 & 0 & - \\
\hline Fentanyl (patch) & 35.6 & 0 & - \\
\hline Swallowing & 25.7 & 0 & - \\
\hline Snorting & 1.0 & 0 & - \\
\hline Injecting & 14.9 & 0 & - \\
\hline Hydrocodone (tablets) & 90.1 & 91.9 & 0.408 \\
\hline Swallowing & 68.3 & 91.9 & 0.046 \\
\hline Snorting & 74.3 & 6.3 & $<0.001$ \\
\hline Injecting & 0 & 0 & - \\
\hline Hydromorphone (all formulations) & 32.7 & 4.6 & 0.001 \\
\hline Swallowing & 6.9 & 4.5 & 0.524 \\
\hline Snorting & 5.9 & 0.9 & 0.472 \\
\hline Injecting & 21.8 & 0 & - \\
\hline Methadone (tablets) & 77.2 & 3.6 & $<0.001$ \\
\hline Swallowing & 27.7 & 3.6 & 0.083 \\
\hline Snorting & 64.4 & 0 & - \\
\hline Injecting & 1.0 & 0 & - \\
\hline Morphine (all formulations) & 53.5 & 4.6 & 0.007 \\
\hline Swallowing & 14.9 & 3.6 & 0.652 \\
\hline Snorting & 17.8 & 0.9 & 0.547 \\
\hline Injecting & 33.7 & 0 & - \\
\hline $\mathrm{OxyContin}^{\circledR}$ (generic/tablets) & 86.1 & 23.6 & 0.002 \\
\hline Swallowing & 25.7 & 22.5 & 0.442 \\
\hline Snorting & 68.3 & 3.6 & $<0.001$ \\
\hline Injecting & 44.6 & 0 & - \\
\hline Other Oxycodone** (tablets) & 83.2 & 50.0 & 0.374 \\
\hline Swallowing & 31.7 & 47.7 & 0.026 \\
\hline Snorting & 68.3 & 1.8 & $<0.001$ \\
\hline Injecting & 3.0 & 0 & - \\
\hline
\end{tabular}

*p-values adjusting for age, race, and gender.

**Includes, for example, Tylox ${ }^{\oplus}$, Percocet ${ }^{\oplus}$, and Percodan ${ }^{\oplus}$.

$15 \%$ of rural participants reported injecting fentanyl patch contents. Preferred route of administration varied by substance and by rural/urban status. Among urban participants, swallowing was the most common route of administration across all substances. In age-, race-, and gender-adjusted analyses, urban participants had significantly higher odds of reporting swallowing hydrocodone and oxycodone than did rural participants. Among rural participants, the preferred route of administration varied according to substance. For hydrocodone, methadone, OxyContin ${ }^{\circ}$, and oxycodone, snorting was the most frequent route of administration. Significantly more rural participants reported snorting hydrocodone, OxyContin ${ }^{\circ}$, and oxycodone than did urban participants, after adjustment for age, race, and gender. For hydromorphone and morphine use among rural drug users, injection was most common. Notably, among rural participants, $67 \%$ of hydromorphone users and $63 \%$ of morphine users had administered the drugs by injection.

\section{Discussion}

Preferred route of administration varied by substance and by rural/urban status. Among urban participants, oral use (swallowing whole or chewing and swallowing) was the most common route of administration. This contrasted sharply with substance-specific variation in routes of administration among rural participants. For example, snorting was the most frequent route of administration for hydrocodone, methadone, OxyContin $^{\circ}$, and oxycodone, while injecting was most commonly used for hydromorphone and morphine administration. After adjustment for age, race, and gender, rural users had significantly higher odds of snorting hydrocodone, OxyContin ${ }^{\circ}$, and oxycodone compared to urban participants.

The increased odds of rural participants to use alternative routes of administration warrant consideration. Previous research has demonstrated that multiple routes of administration are involved in nonmedical prescription opioid use $[40,41,48]$. In fact, our finding on the frequency of snorting OxyContin ${ }^{\circ}$ compared to swallowing and injecting is consistent with the findings of another Kentucky study [39]. That study, conducted in a clinic-based sample from central Kentucky, found that methadone, morphine, and hydromorphone were being administered through various alternative routes, including snorting, chewing, and injecting [39].

Previous literature has posited that the decreased availability of heroin in rural areas may contribute to rural-urban differences in prescription opioid use [11-13]; however, this trend is not apparent in this sample, as nearly twice as many rural participants reported lifetime use of heroin than did urban participants (data not shown). Rather, differences in the prevalence of alternative routes of administration is likely to be more intimately linked to differences in drug problem severity. Previous substance use $[23,25]$ and frequency of current substance use $[26,27]$ are known risk factors for transitioning to injection from other routes of administration. Scores from the Addiction Severity Index [47] indicate that rural participants had much higher drug problem severity than did urban participants, which may have contributed to the rural/urban differences in route of administration evident in this study.

The routes of administration for buprenorphine use among rural participants in this study are consistent with other studies [37,49-52]. For example, the relative 
frequency of buprenorphine snorting compared to injecting in this study is interesting with implications for preventing diversion. Strategies intended to prevent buprenorphine intravenous misuse, like Suboxone ${ }^{\circ}$, may not prevent misuse by alternative routes of administration. The opiate antagonist naloxone contained within Suboxone "guards" against misuse by causing withdrawal symptoms in those who inject or snort it; however, the data are conflicting [53].

The routes of fentanyl administration by rural study participants are also noteworthy. Over $70 \%$ of rural fentanyl users administered the drug orally. Oral administration of fentanyl has been identified within other populations [38,54-56]; however, these studies have generally found oral administration to be rare in comparison with other routes of administration. Oral fentanyl administration can result in a wide range of concentrations in the blood, depending on whether the substance is retained in the oral cavity or swallowed $[56,57]$. Nevertheless, oral fentanyl administration can have fatal consequences, as demonstrated by findings from postmortem studies of fentanyl-related deaths $[55,56]$. Injecting fentanyl, found among $42 \%$ of the fentanyl users in this study, has also been reported in other populations $[55,58,59]$. The frequency of fentanyl injection in this study is concerning given its implications for toxicity and overdose. A fentanyl dose that is survivable following transdermal administration may result in death if administered intravenously [55]. Deaths due to fentanyl overdose following injection can occur at low blood concentrations $(2.0 \mu \mathrm{g} / \mathrm{L}-3.0 \mu \mathrm{g} / \mathrm{L})$ [55,59-61]. These results are especially disconcerting given that ambulance response times are significantly slower in rural areas [62], which may increase the likelihood of fatal overdose.

Perhaps most concerning about the high prevalence of alternate routes of administration is the potential for transmission of blood-borne infections such as HIV and hepatitis B and C. While HIV and hepatitis C $(\mathrm{HCV})$ in particular are transmissible by injecting [63-65], it has also been demonstrated that HCV can be transmitted by sharing equipment used to snort drugs, such as straws [65-67]. A seminal review by Strang and colleagues (1998) discusses various health implications for route of drug use, including nasal ulceration from snorting and respiratory and thrombotic complications, abscesses, and endocarditis from injecting [14]. The health consequences of nonmedical prescription opioid use, as delivered by any route of administration can be severe, entailing potential for physical dependence and addiction, severe respiratory distress, and fatal overdose [7]. Overdose risk, in particular, is compounded by the route of administration [68]. Reports have noted that this is especially problematic in OxyContin ${ }^{\circ}$ use, which was designed to be a slow-release formulation [69].

While this study broadens understanding of rural substance abuse and alternate routes of administration for prescription opioids, it is not without limitations. The data in this study are self-reported and are subject to response bias. This study is also limited by sample size, which prohibited making statistically meaningful ruralurban comparisons for buprenorphine and fentanyl, as well as statistically precise point estimates for certain routes of administration of other substances. The ruralurban comparisons were also complicated by the baseline demographic differences between the two groups. Race-, gender-, and age-adjusted analyses were used in an attempt to isolate the influence of rurality on the outcome of interest; however, a number of unmeasured social, economic, and structural factors may have also influenced the comparison. Also, given the influence of ecological factors such as drug availability and drug price on determining routes of administration [30], the study would have been strengthened by an examination of these characteristics in the rural and urban settings involved.

\section{Conclusions}

This study offers valuable insight into the intricacies of nonmedical rural opioid use in particular. These findings suggest that alternative routes of administration are common among rural drug users, a phenomenon which is likely related to drug problem severity. This finding has implications for rural substance abuse treatment as well as prevention of transition from oral to other routes of use such as snorting and/or injection. The presence of alternative routes of administration among rural drug users also indicates a need for the implementation of harm reduction interventions within this population.

\section{Acknowledgements}

This study is funded by Purdue Pharma L.P.

\section{Author details}

${ }^{1}$ Center on Drug and Alcohol Research, Department of Behavioral Science, University of Kentucky College of Medicine, Lexington, KY, USA. ${ }^{2}$ Department of Behavioral Sciences and Health Education, Emory University Rollins School of Public Health, Atlanta, GA, USA.

\section{Authors' contributions}

AY performed the statistical analysis and drafted the manuscript. All authors read and approved the final manuscript.

\section{Competing interests}

This study is funded by Purdue Pharma L.P. Points-of-view and opinions expressed in this article do not necessarily represent those of Purdue Pharma but represent the opinions of the authors.

Received: 12 August 2010 Accepted: 15 October 2010 Published: 15 October 2010 


\section{References}

1. Miller N, Greenfeld A: Patient characteristics and risks factors for development of dependence on hydrocodone and oxycodone. Am J Ther 2004, 11:26-32.

2. Woolf C, Hashmi M: Use and abuse of opioid analgesics: potentia methods to prevent and deter non-medical consumption of prescription opioids. Curr Opin Investig Drugs 2004, 6:61-66.

3. Substance Abuse and Mental Health Services Administration: Nonmedical use of prescription pain relievers. The NSDUH Report Rockville, MD; Office of Applied Studies 2004.

4. Substance Abuse and Mental Health Services Administration: Results from the 2006 National Survey on Drug Use and Health. Rockville, MD: Office of Applied Studies 2007.

5. Drug Enforcement Administration. OxyContin ${ }^{\oplus:}$ Pharmaceutical Division: Drug Intelligence Brief. Arlington, VA 2002.

6. Hutchinson A: OxyContin Testimony. House Committee on Appropriations, Commerce, Justice, State, and Judiciary 2001.

7. National Institute of Drug Abuse: Research Report Series: Prescription Drugs Abuse and Addiction (NIH Pub No 05-4881). Bethesda, MD National Institute of Drug abuse 2005.

8. McCabe SE, Cranford JA, Boyd CJ, Teter CJ: Motives, diversion and routes of administration associated with nonmedical use of prescription opioids. Addict Behav 2007, 32(3):562-575.

9. Bouhassira D, Lantéri-Minet M, Attal N, Laurent B, Touboul C: Prevalence of chronic pain with neuropathic characteristics in the general population. Pain 2008, 136(3):380-387.

10. Cicero TJ, Surratt $H$, Inciardi JA, Munoz A: Relationship between therapeutic use and abuse of opioid analgesics in rural, suburban, and urban locations in the United States. Pharmacoepidemiol Drug Saf 2007, 16:827-840.

11. Rosenblum A, Parrino M, Schnoll SH, Fong C, Maxwell C, Cleland CM, Magura S, Haddox JD: Prescription opioid abuse among enrollees into methadone maintenance treatment. Drug Alcohol Depend 2007, 90:64-71.

12. Havens JR, Oser CB, Leukefeld CG, Webster JM, Martin SS, O'Connell DJ, Surratt $H L$, Inciardi JA: Differences in Prevalence of Prescription Opiate Misuse Among Rural and Urban Probationers. Am J Drug Alcohol Abuse 2007, 33:309-317.

13. Wunsch MJ, Nakamoto K, Behonick G, Massello W: Opioid deaths in rura Virginia: A description of the high prevalence of accidental fatalities involving prescribed medications. Am J Addict 2009, 18:5-14.

14. Strang J, Bearn J, Farrell M, Finch E, Gossop M, Griffiths P, Marsden J, Wolff $K$ : Route of drug use and its implications for drug effect, risk of dependence and health consequences. Drug Alcohol Rev 1998, 17:197-211.

15. Xian $X$, Jun $L$, Jianling $B$, Rongbin $Y$ : Epidemiology of hepatitis $C$ virus infection among injection drug users in China: Systematic review and meta-analysis. Public Health 2008, 122:990-1003.

16. Chitwood DD, Comerford M, Sanchez JS: Prevalence and Risk Factors for HIV Among Sniffers, Short-Term Injectors, and Long-Term Injectors of Heroin. J Psychoactive Drugs 2003, 35:445-453.

17. Nelson KE, Galai N, Safaeian M, Strathdee SA, Celentano DD, Vlahov D: Temporal trends in the incidence of human immunodeficiency virus infection and risk behavior among injection drug users in Baltimore, Maryland, 1988-1998. Am J Epidemiol 2002, 156:641-653.

18. Alter MJ: Prevention of spread of hepatitis C. Hepatology 2002, 36:S93-S98.

19. Gossop M, Griffiths P, Powis B, Strang J: Severity of dependence and route of administration of heroin, cocaine and amphetamines. Br J Addict 1992, 87:1527-1536

20. Gossop M, Griffiths P, Powis B, Strang J: Cocaine: patterns of use, route of administration, and severity of dependence. Br J Psychiatry 1994, 164:660-664

21. Strang J, Griffiths P, Powis B, Gossop M: Heroin chasers and heroin injectors: differences observed in a community sample in London, UK. Am J Addict 1999, 8:148-160.

22. Gossop M, Griffiths P: Frequency of non-fatal heroin overdose: Survey of heroin users recruited in non-clinical settings. Br Med J 1996, 313:402-402.

23. Neaigus A, Miller M, Friedman SR, Hagen DL, Sifaneck SJ, Ildefonso G, des Jarlais DC: Potential risk factors for the transition to injecting among non-injecting heroin users: a comparison of former injectors and never injectors. Addiction 2001, 96:847-860.
24. Abelson J, Treloar C, Crawford J, Kippax S, van Beek I, Howard J: Some characteristics of early-onset injection drug users prior to and at the time of their first injection. Addiction 2006, 101:548-555.

25. Roy E, Haley N, Leclerc P, Cédras L, Blais L, Boivin JF: Drug injection among street youths in Montreal: predictors of initiation. J Urban Health 2003 80:92-105

26. Neaigus A, Gyarmathy A, Miller M, Frajzyngier VM, Friedman SR, des Jarlais DC: Transitions to Injecting Drug Use Among Noninjecting Heroin Users. J Acquir Immune Defic Syndr 2006, 41(4):493-503.

27. Fischer B, Manzoni P, Rehm JR: Comparing Injecting and Non-Injecting Illicit Opioid Users in a Multisite Canadian Sample (OPICAN Cohort). Eur Addict Res 2006, 12:230-239.

28. Fuller CM, Vlahov D, Ompad DC, Shah N, Arrio A, Strathdee SA: High-risk behaviors associated with transition from illicit non-injection to injection drug use among adolescent and young adult drug users: a case-control study. Drug Alcohol Depend 2002, 66:189.

29. Bravo MJ, Barrio G, de la Fuente L, Royuela L, Domingo L, Silva T: Reasons for selecting an initial route of heroin administration and for subsequent transitions during a severe HIV epidemic. Addiction 2003, 98(6):749-760

30. Firestone $M$, Fischer $B$ : A qualitative exploration of prescription opioid injection among street-based drug users in Toronto: Behaviours, preferences and drug availability. Harm Reduct J 2008, 5:30.

31. Sherman SG, Smith L, Laney G, Strathdee SA: Social influences on the transition to injection drug use among young heroin sniffers: a qualitative analysis. Int J Drug Policy 2002, 13:113.

32. Van Ameijden EJ, Van Den Hoek JA, Hartgers C, Coutinho RA: Risk factors for the transition from noninjection to injection drug use and accompanying AIDS risk behavior in a cohort of drug users. Am $J$ Epidemiol 1994, 139:1153-1163.

33. Strang J, Griffiths P, Gossop M: Heroin in the United Kingdom: different forms, different origins, and the relationship to different routes of administration. Drug Alcohol Rev 1997, 16:329-337.

34. Cicero TJ, Surratt $H$, Inciardi JA, Munoz A: Relationship between therapeutic use and abuse of opioid analgesics in rural, suburban, and urban locations in the United States. Pharmacoepidemiol Drug Saf 2007, 16:827-840.

35. Strang J, Des Jarlais DC, Griffiths P, Gossop M: The study of transitions in the route of drug use: The route from one route to another. $\mathrm{Br} J$ Addict 1992, 87:473-483.

36. De la Fuente L, Saavedra P, Barrio G, Royuela L, Vicente J: Temporal and geographic variations in the characteristics of heroin seized in Spain and their relation with the route of administration. Spanish Group for the Study of the Purity of Seized Drugs. Drug Alcohol Depend 1996, 40:185-194.

37. Hakansson A, Medvedeo A, Andersson M, Berglund M: Buprenorphine Misuse among Heroin and Amphetamine Users in Malmo, Sweden: Purpose of Misuse and Route of Administration. Eur Addict Res 2007, 13:207-215.

38. Liappas IA, Dimopoulos NP, Mellos E, Gitsa OE, Liappas Al, Rabavilas AD: Oral transmucosal abuse of transdermal fentanyl. J Psychopharmacol 2004, 18:277-280.

39. Passik SD, Hays L, Eisner N, Kirsh KL: Psychiatric and Pain Characteristics of Prescription Drug Abusers Entering Drug Rehabilitation. J Pain Palliat Car Pharmacother 2006, 20:5-13.

40. Back SE, Payne RA, Waldrop AE, Smith A, Reeves S, Brady KT: Prescription opioid aberrant behaviors: a pilot study of sex differences. Clin J Pain 2009, 25:477-484

41. Green TC, Grimes Serrano JM, Licari A, Budman SH, Butler SF: Women who abuse prescription opioids: Findings from the Addiction Severity IndexMultimedia Version ${ }^{\circledR}$ Connect prescription opioid database. Drug Alcohol Depend 2009, 103:65-73.

42. United States Department of Agriculture: 2003 Rural-Urban Continuum Codes for Kentucky. United States Department of Agriculture 2003, August 18, 2003 edition

43. County Economic Status, Fiscal Year 2010: Appalachian Kentucky. [http:// www.arc.gov/reports/region_report.asp?FIPS=21999\&REPORT_ID=33].

44. United States Census Bureau: United States Census 2000. 2000

45. Barendregt C, Van der Poel A, Van de Mheen D: Tracing Selection Effects in Three Non-Probability Samples. Eur Addict Res 2005, 11:124-131. 
46. Sheehan DV, Lecrubier $Y$, Sheehan $K H$, Amorim $P$, Janavs J, Weiller $E$, Hergueta T, Baker R, Dunbar GC: The Mini-International Neuropsychiatric Interview (M.I.N.I.): the development and validation of a structured diagnostic psychiatric interview for DSM-IV and ICD-10. J Clin Psychiatry 1998, 59(Suppl):22-33

47. McLellan AT, Kushner H, Metzger D, Peters R, Smith I, Grissom G, Pettinati H, Argeriou M: The Fifth Edition of the Addiction Severity Index. J Subst Abuse Treat 1992, 9:199-213.

48. McCabe SE, Boyd CJ, Teter CJ: Subtypes of nonmedical prescription drug misuse. Drug Alcohol Depend 2009, 102:63-70.

49. Barrau K, Thirion X, Micallef Jl, Chuniaud-Louche C, Bellemin Ba, San Marco JL: Comparison of methadone and high dosage buprenorphine users in French care centres. Addiction 2001, 96:1433-1441.

50. Obadia Y, Perrin V, Feroni I, Vlahov D, Moatti J-P: Injecting misuse of buprenorphine among French drug users. Addiction 2001, 96:267-272.

51. Vidal-Trecan Gl, Varescon I, Nabet N, Boissonnas A: Intravenous use of prescribed sublingual buprenorphine tablets by drug users receiving maintenance therapy in France. Drug Alcohol Depend 2003, 69:175.

52. Strang J: Abuse of buprenorphine (Temgesic) by snorting. BMJ (Clin Res Ed) 1991, 302:969-969.

53. National Drug Intelligence Center: Intelligence Bulletin: Buprenorphine: Potential for Abuse. 2004.

54. Arvanitis ML, Satonik RC: Transdermal fentanyl abuse and misuse. Am J Emerg Med 2002, 20:58-59.

55. Martin TL, Woodall KL, McLellan BA: Fentanyl-Related Deaths in Ontario, Canada: Toxicological Findings and Circumstances of Death in 112 Cases (2002-2004). J Anal Toxicol 2006, 30:603-610.

56. Woodall KL, Martin TL, McLellan BA: Oral Abuse of Fentanyl Patches (Duragesic $^{\oplus}$ ): Seven Case Reports. J Forensic Sci 2008, 53:222-225.

57. Streisand JB, Varvel JR, Stanski DR, Le Maire L, Ashburn MA, Hague BI, Tarver SD, Stanley TH: Absorption and bioavailability of oral transmucosal fentanyl citrate. Anesthesiology 1991, 75:223-229.

58. Lilleng PK, Mehlum LI, Bachs L, Morild I: Deaths After Intravenous Misuse of Transdermal Fentanyl. J Forensic Sci 2004, 49:1364-1366.

59. Tharp AM, Winecker RE, Winston DC: Fatal intravenous fentanyl abuse: four cases involving extraction of fentanyl from transdermal patches. Am J Forensic Med Pathol 2004, 25:178-181.

60. Kuhlman JJ Jr, McCaulley R, Valouch TJ, Behonick GS: Fentanyl Use, Misuse, and Abuse: A Summary of 23 Postmortem Cases. J Anal Toxicol 2003, 27:499-504.

61. Reeves MD, Ginifer CJ: Fatal intravenous misuse of transdermal fentanyl. Med J Aust 2002, 177:552-553.

62. Carr BG, Caplan JM, Pryor JP, Branas CC: A meta-analysis of prehospital care times for trauma. Prehosp Emerg Care 2006, 10:198-206.

63. MacDonald M, Crofts N, Kaldor J: Transmission of hepatitis C virus: rates, routes, and cofactors. Epidemiol Rev 1996, 18:137-148.

64. van den Hoek JA, van Haastrecht HJ, Goudsmit J, de Wolf F, Coutinho RA: Prevalence, incidence, and risk factors of hepatitis $C$ virus infection among drug users in Amsterdam. J Infect Dis 1990, 162:823-826.

65. Mathers BM, Degenhardt L, Phillips B, Wiessing L, Hickman M, Strathdee SA, Wodak A, Panda S, Tyndall M, Toufik A, Mattick RP: Global epidemiology of injecting drug use and HIV among people who inject drugs: a systematic review. Lancet 2008, 372:1733-1745.

66. Aaron S, McMahon JM, Milano D, Torres L, Clatts M, Tortu S, Mildvan D, Simm M: Intranasal Transmission of Hepatitis C Virus: Virological and Clinical Evidence. Clin Infect Dis 2008, 47:931-934.

67. McMahon JM, Simm M, Milano D, Clatts M: Detection of hepatitis C virus in the nasal secretions of an intranasal drug-user. Ann Clin Microbiol Antimicrob 2004, 3:6-6.

68. Hall AJ, Logan JE, Toblin RL, Kaplan JA, Kraner JC, Bixler D, Crosby AE, Paulozzi LJ: Patterns of abuse among unintentional pharmaceutical overdose fatalities. JAMA 2008, 300(22):2613-20.

69. National Institute of Drug Abuse: InfoFacts: Prescription and Over-thecounter medications. Bethesda, MD: National Institute of Drug Abuse 2009 [http://www.nida.nih.gov/PDF/Infofacts/PainMed09.pdf], Accessed October 8,2010

doi:10.1186/1477-7517-7-24

Cite this article as: Young et al: Route of administration for illicit prescription opioids: a comparison of rural and urban drug users. Harm Reduction Journal 2010 7:24

\section{Submit your next manuscript to BioMed Central and take full advantage of:}

- Convenient online submission

- Thorough peer review

- No space constraints or color figure charges

- Immediate publication on acceptance

- Inclusion in PubMed, CAS, Scopus and Google Scholar

- Research which is freely available for redistribution 